\title{
O mar onduloso da memória em Conceição Evaristo
}

\author{
Maria Nazareth Soares Fonseca \\ Pontifícia Universidade Católica de Minas Gerais (Belo Horizonte, Brasil)
}

\begin{abstract}
RESUMO: O TEXTO PROCURA RESSALTAR O MODO COMO A ESCRITORA CONCEIÇÃO EVARISTO, PARTICULARMENTE NO ROMANCE BECOS DA MEMÓRIA, PROCURA RESGATAR AS LEMBRANÇAS DAS GENTES SIMPLES QUE VIVEM EM LUGARES MARCADOS PELA EXPERIÊNCIA DURA DA POBREZA E DA EXCLUSÃO. A COMPARAÇÃO ENTRE BECOS DA MEMÓRIA E TEXACO, DO ESCRITOR MARTINIQUENSE PATRICK CHAMOISEAU, INTENTA ACENTUAR QUE, NOS DOIS ROMANCES, O REPRIMIDO, O SILENCIADO ASSUMEM A CENA DA ESCRITA, RASURANDO, DE ALGUM MODO, O PRÓPRIO ESPAÇO EM QUE CIRCULAM.
\end{abstract}

ABSTRACT: THIS PAPER SEEKS TO HIGHLIGHT HOW THE WRITER CONCEIÇÃO EVARISTO ATTEMPTS TO RETRIEVE MEMORIES OF ORDINARY PEOPLE WHO LIVE IN PLACES MARKED BY THE HARSH EXPERIENCE OF POVERTY AND EXCLUSION, PARTICULARLY IN HER NOVEL BECOS DA MEMÓRIA. BY COMPARING BECOS DA MEMÓRIA AND TEXACO, BY THE MARTINICAN WRITER PATRICK CHAMOISEAU, I AIM TO EMPHASIZE THAT, IN THESE TWO NOVELS, THOSE WHO HAVE BEEN REPRESSED AND SILENCED TAKE CENTRE STAGE THROUGH THE WRITING PROCESS, AND THEREBY, SOMEHOW, DRAFT THE VERY SPACE IN WHICH THEY CIRCULATE.

PALAVRAS-CHAVE: CONCEIÇÃO EVARISTO, PATRICK CHAMOISEAU, ROMANCE, POBREZA, EXCLUSÃO.

KEYWORDS: CONCEIÇÃO EVARISTO, PATRICK CHAMOISEAU, NOVEL, POVERTY, EXCLUSION. 


\section{Recordar épreciso. \\ O movimento vaivém nas águas-lembranças dos meus marejados olhos transborda-me a vida, salgando-me o rosto e o gosto. \\ Conceição Evaristo}

s versos do poema "Recordar é preciso", do livro Poemas da recordação e outros movimentos (2008), tomados como epígrafe, aludem a uma feição que está semprepresente na produção literária de Conceição Evaristo. Seus textos, poemas e narrativas são elaborados com forte apelo à memória, à recuperação de dados de uma história que está em sua própria vida, e na de espaços marcados pelas dificuldades vividas pelos descendentes de escravos, particularmente por aqueles que sofrem mais intensamente as agruras características dos socialmente marginalizados. Para vencer os traumas causados por essa exclusão, Conceição Evaristo escreve, cria mundos possíveis, porque, como dizem os versos de seu poema: "Recordar é preciso".

Em outro poema, "Do velho e do jovem" (2005, p. 72), publicado também no referido livro, a escritora celebra tradições características dos espaços marcados por fortes tradições herdadas dos africanos. O valor da experiência vivida marca o respeito ao que se aprende dos mais velhos e ao que os mais experientes passam aos mais jovens. O diálogo poético entre o velho e o novo celebra o acolhimento dos sinais da passagem do tempo que, no rosto de um velho, são marcas da experiência acumulada ao longo dos anos. As rugas no rosto velho tornam-se letras, são "palavras escritas na carne" que simbolizam o "abecedário do viver" (p. 72). As imagens celebram, no poema, as marcas da experiência vivida e intentam ressaltar o contraste com o "frescor da pele" da face do jovem e com as muitas histórias de que fazem parte personagens anônimas como Neide do Brás, Cíntia da Lapa, Piter do Estácio, Mabel do Pelô e outras conclamadas de Santana e de Belo Horizonte. Todas essas personagens, sujeitos de uma história de "falas silenciadas" (p. 72), compõem as lembranças que o poema assume, entrelaçando o "velho tempo" que se mistura ao novo para "eternizar as palavras da liberdade ainda agora [...]" (p. 73).

Seguindo uma característica da obra literária de Conceição Evaristo, o poema retoma os relatos de experiência passadas de geração em geração, histó- 
rias deixadas por sujeitos anônimos por meio de palavras contadas, de sinais que o corpo assume com as marcas no rosto, os calos das mãos, mas também com o frescor da pele e o brilho dos olhos dos mais jovens.

Um outro poema de Evaristo, "Vozes mulheres" (2008, p. 10-11), recolhe as experiências deixadas por diferentes tradições de mulheres, transmitidas em diversos significantes. Personagens de uma história que remete ao comércio da escravidão, a bisavó e a avó passam às suas descendentes dados de uma história de sofrimento e submissão que ajudarão a compor outras histórias nas quais o silêncio e os lamentos poderão produzir outros sentidos.

A voz de minha bisavó ecoou

criança

nos porões do navio.

Ecoou lamentos

de uma infância perdida.

A voz de minha vó

ecoou obediência

aos brancos - donos de tudo.

A voz de minha mãe

ecoou baixinho revolta

no fundo das cozinhas alheias

debaixo das trouxas

roupagens sujas dos brancos

pelo caminho empoeirado

rumo à favela.

A minha voz ainda

ecoa versos perplexos

com rimas de sangue

e

fome. 
A voz de minha filha

recolhe todas as nossas vozes

recolhe em si

as vozes mudas caladas

engasgadas nas gargantas.

A voz de minha filha

recolhe em si

a fala e o ato.

O ontem - o hoje - o agora.

$\mathrm{Na}$ voz de minha filha

se fará ouvir a ressonância

o eco da vida - liberdade.

(EVARISTO, 2008, p. 10-11)

A voz poética retoma, nos versos do poema, a história da "bisavó" cunhada pelo sofrimento "nos porões do navio" e pelos lamentos de uma "infância perdida". Passa esse legado a outra mulher, à avó, marcada pela submissão ao trabalho forçado, pela obediência a ordens a que era difícil resistir, dada a condição imposta pelo sistema legitimado pelos "donos de tudo" (p. 10). Dos silêncios dessas mulheres chegam os ecos de uma história que remete ao desenvolvimento do capitalismo comercial no Atlântico e às transações comerciais que tinham os africanos escravizados como possibilidade de fazer crescer uma economia comercial em que a África, o Brasil e Portugal, e eventualmente a Inglaterra, eram tidos como principais agentes (MILLER, Apud FIGUEIREDO, 2009, p.37).

O poema resgata, assim, a vOz dos que sofreram essa história e a retoma a partir dos dados que, em silêncio, as mulheres passam às suas descendentes, também personagens de outras histórias de submissão e sofrimento. A bisavó e a avó costuram, com lamentos e sofrimentos, uma história que vem dos porões dos navios negreiros, das lidas nas casas-grandes, nas lavouras, no comércio de ganho, nas ruas das cidades. O legado de silêncios e de trabalho é assumido pela voz da mãe, habitante do "fundo das cozinhas alheias", significada ainda pelo trabalho penoso - lavar, passar, cozinhar, cuidar - repetido exaustivamente to- 
dos os dias. Na história da mãe, os sofrimentos herdados deslocam-se para os espaços periféricos das cidades, para as favelas e para outros locais caracterizados por outras formas de aprisionamentos das vozes silenciadas.

Ao assumir esse legado de dor e lamentos, o eu-poético "ecoa versos perplexos / com rimas de sangue e fome", transmudando em escrita libertadora os lamentos, as dores, os silêncios. Escrever o poema é, assim, a construção de um outro legado a ser deixado à filha que "recolhe todas as nossas vozes recolhe em si as vozes mudas caladas" (p. 10-11), porque, inserida em outro tempo e espaço, poderá assumir o desejo latente de liberdade, dando-lhe outros tons, deslocando o silêncio para assumir as vozes-mulheres de sua tradição. $\mathrm{Na}$ alquimia da escrita, os silêncios, as falas e os atos podem possibilitar a geração de outros relatos nos quais irão proliferar "os ecos da vida-liberdade" (p. 11). Pode-se dizer que as várias memórias se mostram no poema como uma trança que o poema tece ao resgatar as histórias de mulheres e que, ao serem recuperadas, figurativamente, essas diferentes histórias que remetem à bisavó, à avó, à mãe articulam uma nova história no campo da escrita, no da literatura, capaz de formular novas vivências e experiências a serem passadas à filha.

As histórias, tecidas como em uma trança, recolhem as marcas deixadas por experiências que remetem à tradição de trançar, pentear, resgatando as perplexidades advindas do sofrimento vivido, mas também o legado de uma história de lutas, significada pelo corpo e transformada em motivação de escrita. Nas experiências da bisavó, da avó e da mãe resgatam-se, ainda, elementos de uma disciplina que fabrica "corpos submissos" porque, como nos diz Foucault (1977, p. 127), é uma transformação imposta aos corpos para torná-los “dóceis" e exercitados para o trabalho. Essa transformação insiste na sujeição, na domesticação, e estabelece "o elo coercitivo entre uma aptidão aumentada e uma dominação acentuada" (FOUCAULT, 1977, p. 127). Por isso, no poema, a sujeição de corpos domesticados pelas ordens do sistema escravocrata e do capitalismo é transmudada em capacidade de resposta que, inscrita na perplexidade, é capaz de atar o "ontem - o hoje - o agora” (EVARISTO, 2005, p. 11), para produzir outros atos e novas falas, essas, sim, libertadoras.

Outros poemas de Evaristo montam-se com a mesma preocupação de resgatar memórias silenciadas, de acolher traços e lembranças de experiências vividas em espaços de exclusão, com o olhar atento às funções desempenhadas pelas mulheres como cuidadoras, responsáveis por atos que disseminam 
a vida. Não é por acaso que em vários poemas da escritora o cuidar do corpo é tomado como motivação para a escrita, porque nessa ação acentuam-se elementos de um trabalho de resgate e assunção inscritos no corpo para torná-lo capaz de exercer ações mais prazerosas, trabalho que, lido como espaço de mudanças, está construído no poema "Para a menina" (1998, p. 35):

Desmancho as tranças da menina

e os meus dedos tremem

medo nos caminhos

repartidos de seus cabelos

Lavo o corpo da menina

e as minhas mãos tropeçam

dores nas marcas - lembranças

de um chicote traiçoeiro.

Visto a menina

e aos meus olhos

a cor de sua veste

insiste e se confunde

com o sangue que escorre

do corpo - solo de um povo

Sonho os dias da menina

e a vida surge grata

descruzando as tranças

e a veste surge grata

justa e definida

e o sangue se estanca

passeando tranquilo

nas veias de novos caminhos, esperança.

O eu-poético, como no poema anterior, acolhe lembranças penosas e amargas ao cuidar da menina, desmanchando-lhe as tranças, lavando e vestindo o seu corpo para expurgar os medos, as dores e as marcas que remetem a um 
passado significado pelas tormentas, por uma "anatomia política" e por uma "mecânica do poder" (FOUCAULT, 1977, p. 127). No poema, a menina, metaforicamente, encarna a esperança em "novos caminhos" postos em direção ao futuro, quando o corpo e os cabelos negros poderão assumir significados distantes dos ditados por uma sintaxe corporal em que cabelos, lábios, cor, cheiro e texturas corporais são marcados por estereótipos negativos. Nessa direção, é possível ver no poema "Para uma menina" a intenção de tirar do corpo negro as "lembranças de um chicote traiçoeiro" (EVARISTO, 1998, p. 35), para que esse corpo possa receber "a veste farta, justa e definida" capaz de acentuar "os novos caminhos" para este mesmo corpo.

É importante acentuar que, nos dois poemas, "Vozes-mulheres" e "Para uma menina", a construção de um outro tempo mostra-se ressignificada pela esperança que se instala num corpo feminino, mais especificamente, no corpo de uma criança, da filha que recebe a herança das gerações anteriores à sua para lhe dar um novo sentido. Todavia, recupera-se, também, nos dois poemas, uma relação entre mãe e filha muitas vezes interditada durante a escravidão, uma vez que a mulher negra quase nunca podia cuidar bem de sua prole após o período da amamentação, porque a mulher voltava ao trabalho bem antes do desmame e a criança, ainda bem nova, era levada a exercer pequenos trabalhos, legitimando, assim, a autoridade dos senhores, donos dos seus escravos (MOT'T, 1989). Como acentua Mott, o destino das crianças escravas era, portanto, definido pelo regime do dono de sua mãe e mesmo a tradição das amas-de-leite, das escravas que cuidavam dos filhos dos senhores, não alterou a relação das servas com os seus filhos pequenos, geralmente amarrados às costas das mães, nos trabalhos na lavoura ou entregues a velhas e a meninas de 6 a 7 anos (MOT'T, 1989, p. 88).

Muitos traços da relação entre a mãe escrava e seus filhos revelam-se nos poemas de Evaristo, particularmente no modo como a poetisa acolhe os fatos, ressignificando-os a partir de uma olhar lançado sobre os destinos das mulheres. E, ao recuperar as vozes-mulheres, ela permite que em seus poemas sejam registradas as memórias de personagens anônimas cujas vidas estão marcadas pelos dados de uma história que, iniciada nos tempos do tráfico negreiro, distende-se por diferentes espaços da sociedade em que vivemos.

É o que pode ser acompanhado na trajetória da personagem Ponciá Vicêncio, do romance de mesmo nome, publicado em 2003. A personagem Ponciá, 
em busca de significados que possam explicar a sua origem, aciona memórias e relatos de descendentes de africanos escravizados, lidando com desencontros, abandonos e rupturas, de certo modo recuperando traços da história dos que se ligam, histórica e eticamente, à grande massa de africanos escravizados trazida para o Brasil. Neste romance e também em Becos da memória (2006) ${ }^{1}$ expressa-se a intenção de recolha de memórias que transitam em espaços marginalizados, de forma oral na maioria das vezes, porque seus informantes não costumam ter acesso à escrita, já que ler e escrever nesses espaços é um privilégio de poucos.

Tanto em Ponciá Vicêncio quanto em Becos da memória, Conceição Evaristo vasculha a experiência de pessoas ocupantes de espaços periféricos, que podem ser assumidos como aqueles que, como muitos grupos, têm uma forte bagagem de memória nem sempre considerada pela História, porque esta, assumindo um outro movimento, acaba por desligitimar o passado vivido (NORA, 1993, p. 9).

Vasculhar os fragmentos de memórias, os rastros de lembranças recuperadas pela voz, pelas histórias que transitam entre as pessoas simples é o que faz Evaristo em Becos da memória. O título já revela tratar-se de lugares por onde as lembranças ainda transitam mais livremente, mesmo correndo o risco de serem esquecidas, pois cada vez mais se impõe um silenciamento às histórias que passam de boca a boca, às experiências vividas por pessoas que ocupam suas margens, os espaços periféricos nas grandes cidades. O silêncio que é imposto às experiências dos que vivem em lugares de pouca visibilidade no mapa arquitetônico dos grandes centros urbanos é, neste romance, interrompido pelo cuidado em se acompanhar a vida dos habitantes.

A intenção de contar uma história de descendentes de escravos que migram para um grande centro, passando a ocupar o espaço da favela, pode ser posta em comparação com uma outra narrativa que trata de questão semelhante, ainda que a realidade enfocada seja a de um país das Antilhas Francesas. O romance Texaco, do martinicano Patrick Chamoiseu, tal como Becos da memória assume a tarefa de contar as histórias dos habitantes de uma favela que nasce no entorno de uma empresa petrolífera, A favela Texaco será, de

1. Recupero, aqui, muitas das observações que estão no texto do prefácio, de minha autoria, publicado como introdução ao romance, em 2006. 
forma indireta, a responsável pela decisão da prefeitura de demolir os barracos sob a justificativa de que o local é insalubre. Ironicamente, é neste lugar que a história dos descendentes de africanos escravizados está preservada, porque ela se mantém com os relatos que explicam a existência de Texaco e o que o lugar significa para os seus moradores. A estória do lugar, uma história coletiva do "nós", ajuda a tecer os relatos das pessoas simples que habitam a região desde antes da chegada dos que somente se interessam pela exploração da riqueza do solo, sem nenhuma preocupação com os habitantes do lugar. Marie-Sophie Laborieux se encarrega de narrar a história dos que vivem em sua comunidade e, por isso, conta ao representante da prefeitura a história do lugar, valendo-se da única arma de que dispõe: a persuasão de sua palavra com a qual deveria "travar sozinha a decisiva batalha pela sobrevivência de Texaco (CHAMOISEAU, 1993, p. 34).

Ao utilizar estratégia semelhante à de Chamoiseau, Conceição Evaristo procura, em seu romance, alçar do esquecimento as histórias dos habitantes de uma favela que tem traços bem próximos aos que ela, a escritora, viveu em sua infância. É pela capacidade de ouvir histórias, de prestar bem atenção em tudo que seus olhos alcançam, que o acervo de memórias será salvo do esquecimento, pela decisão de guardar as histórias que ouvia, "as histórias que as mulheres, às vezes, contavam baixinho" (p. 44). É pelo registro das memórias silenciadas que os contornos do coletivo se reiteram, nos dois romances, exibindo os gestos de uma escrita que se fortalece com as marcas deixadas no corpo, pela experiência vivida. Nos dois romances, o sujeito que assume a ação de narrar o que expressam as vozes excluídas sabe que o registro das experiências vividas pelos que sofreram os desmandos dos poderosos expõe as feridas abertas no próprio corpo e, que, em razão disso, a escrita se constrói, não só como um alívio, mas também como denúncia. Por isso, como se acentua em versos do poema tomado como epígrafe a este texto, "recordar é preciso", para salvar do esquecimento as histórias de vida que se cruzam nos espaços significados pela pobreza, registrando o abandono, mas também a força das lembranças que precisam ser ouvidas e recontadas. Evaristo, como Chamoiseau, sabe que sua tarefa de escritora está em se voltar a lugares em que a memória continua viva, porque_se preserva na contação, na experiência significativa do narrar. Sua escrita colada na vivência certamente consegue deslocar o olhar meramente contemplativo do leigo, uma vez que o instiga a 
perceber, nos relatos, o esforço dos que lutam por sobreviver em condições intensamente desfavoráveis.

Particularmente em Becos da memória anuncia-se um movimento narrativo marcado pela denúncia das mazelas de um projeto urbano que não conseguiu resolver a demanda dos excluídos, dos bolsões de pobreza que colocam em xeque o ranço positivista de slogans como "ordem e progresso". A vivência da penúria não esmorece, todavia, o traço de sensibilidade que se mostra neste romance e que também pode ser comparado ao tom assumido pela voz narradora de Texaco, quando deixa bem clara uma norma seguida pelos habitantes dessa favela: "nunca medimos a vida com o metro de nossas dores. Assim, eu mesma, Marie-Sophie, apesar da água de minhas lágrimas, sempre vi o mundo sob uma luz favorável" (p. 3). Assim, nos dois romances, os dados de uma história maior, a de um aglomerado de barracos cambiantes se tecem com a experiência de pessoas expostas à dura pobreza, as quais, contudo, não deixam arrefecer o desejo de continuar vivendo. Por isso, escrever pode se tornar uma ferramenta útil para talhar o vasto painel de lembranças calcadas na "experiência da pobreza", vividas por quem soube observar, com olhos atentos e condoídos, os becos de uma coletividade favelada e os seus habitantes.

Em Becos da memória, Maria-Nova, a menina de olhar atento retém as imagens que, mais tarde, a ajudarão a "contar tudo aquilo ali" (p. 35), a costurar as muitas histórias que ia colecionando com os olhos muito atentos aos detalhes da contação. A escrita do romance, assim, recupera os fatos recordados e acolhidos com a generosidade de quem pode observar a vida daqueles que formam o grande mosaico de excluídos, com o cuidado de preservar os detalhes de cada história, como a de Bondade, o narrador de histórias tristes, contadas "com lágrimas nos olhos" (p. 39), e de outras alegres, com as quais assumia a alegria das crianças; ou como a experiência do Negro Alírio, que ajudava os companheiros a decifrarem os deveres e as ordens que os diversos locais de trabalho dispunham para os operários; ou o modo como a Vó Rita distribuía com os outros seu coração generoso. Para se preparar, Maria-Nova seguia as palavras do Tio Tatão, quando lhe dizia ser "preciso ter os ouvidos, os olhos e o coração abertos" (p. 103) para guardar as coisas a serem contadas por ela.

No universo de vidas tão sofridas e de histórias construídas de carências e abandonos, as ações, impulsionadas pelo amor disseminado na comunidade em gestos singelos e comoventes, formam um lastro que acolhe os que têm 
fome e são expostos à violência e à "doença que mina os corpos". Nesse contexto, a Vó Rita, Bondade e o Negro Alírio figuram como pessoas solidárias, preocupadas com o outro e, por isso, irão aquecer o desejo de compor um livro com aquelas vidas que driblam a fome, sofrem as tormentas da pobreza e com a brutalidade dos desmoronamentos causados pelas chuvas e pela chegada dos tratores que expulsavam todos das áreas a serem ocupadas por outro tipo de construção.

É pelo olhar de Maria-Nova, que ficou "em seu barracão caiado de branco" (p. 167), quando quase todos os outros já haviam sido derrubados, que o leitor pode adentrar espaços marcados pela exclusão, pelos "horrores da miséria, a grande doença que mina os corpos, a saúde e a esperança". É por seu olhar que se visita a paisagem modificada pelos tratores que soterravam "os restos de barracos rapidamente" e pelas alterações deixadas pelas chuvas, responsáveis pelos desbarrancamentos (p. 119). O Buracão, que ameaçava os moradores, impedia que a vida pudesse ser como fora um dia. O Buracão, como uma grande boca insaciável, engolia "bêbados e crianças distraídas" (119) e, ao mesmo tempo expulsando os moradores para mais longe. O grande buraco inverte a imagem do útero, porque se relaciona com o perigo para bêbados e crianças e com a morte das vítimas sugadas por ele, como a de Cidinha-Cidoca, que não suportou os apelos do grande colo, cujo fundo se amaciava com plantas e lama e convidava a um sono de que não se acorda jamais. Metaforicamente, o Buracão ratifica na narrativa os sinais de morte que a pobreza exibe todos os dias e, além dela, a certeza da expulsão para lugares mais distantes, talvez mais pobres ainda, que se concretizava com a presença dos caminhões, que "chegavam de manhã e até tarde da noite levavam as famílias" (p. 151). A morte anunciada pela miséria, pelo Buracão e pelos desmoronamentos provocados pela chuva toma forma na expulsão dos miseráveis, pois certamente a pobreza os acompanharia na nova morada. E os espaços reconstruídos pela narrativa destacam, sobretudo, o sofrimento, porque esse é o estigma da vida dos moradores da favela.

O contraponto privilegiado pelo romance procura dar conta da fragmentação do cenário em que as histórias se passam. A fragmentação faz-se linguagem de um espaço social que não conhece as grandes avenidas, as ruas abertas em obediência a um plano arquitetônico. O recurso narrativo compõe, de certa forma, uma estética que se acentua com os elos que se vão formando 
à revelia de uma linha mestra, tal como os barracos que nascem procurando ocupar os parcos espaços ainda não habitados. Não é o plano, a planta-baixa, que define o processo narrativo privilegiado. É a necessidade de resgatar as histórias que as lembranças vão recompondo, muitas vezes associando pedaços de umas ao que sobra de outras. As lembranças, os casos tristes e as cenas de alegria, nela se registram palavras de ordem que, ditas por algumas personagens, revelam a certeza de que, ao serem narradas as histórias de um tempo passado, a intenção de denúncia não se omite nos relatos de experiência.

Assegura-nos Walter Benjamin que "a experiência que passa de pessoa a pessoa é a fonte a que recorrem os narradores” (BENJAMIN, 1987, p. 198). Lamentando a morte da arte de narrar, o teórico alemão a considera expulsa das sociedades modernas, e rarefeita até mesmo em enclaves étnicos de predominância oral, com a intromissão dos aparelhos que, sedutoramente, silenciam as conversas e impõem sujeição aos corpos. O mundo da experiência comunicável fica cada vez mais pobre, porque se perde a sua dimensão utilitária e os contadores de histórias são substituídos por quem não consegue falar exemplarmente sobre suas preocupações mais importantes. Pensando num mundo em crise, o teórico alemão fixou-se no cenário devastado pela Segunda Guerra Mundial. Prisioneiro do lugar de onde emitiu a sua melancólica visão sobre a morte da narrativa de experiência, não pode registrar os espaços que, por injunções da própria modernidade, continuam a preservá-la.

Em Becos da memória, Conceição Evaristo procura restaurar esses lugares em que a palavra viva circula, mesclada a outras linguagens que, ao mesmo tempo em que desvelam as "memórias subterrâneas", expõem-nas em suportes acessíveis somente aos que podem ler. Inscritas nesse conflito, as memórias recuperam cenas de vidas que preservam expressões de amor, afeto e compaixão. Sentimentos que, aos poucos, vão rareando nas relações entre as pessoas e sufocando brutalmente os restos de experiência comunicável que o romance valoriza. E a favela, resgatada pelo traço da escrita, mostra-se como o lugar em que viveram Vó Rita, Bondade, Negro Alírio, Maria-Velha e Maria-Nova, a colecionadora de histórias eternizadas pela ferramenta que propiciou contar tudo o que ela ouviu. "Contar as histórias dela e dos outros" (p.35), para assumir o gesto que preenche as páginas do seu livro. 


\section{Referências bibliográficas}

BENJAMIN, Walter. O narrador: considerações sobre a obra de Nikolai Leskov. In: Obras escolbidas - magia e técnica, arte e política. Trad. Sérgio Paulo Rouanet, 3. ed. São Paulo: Brasiliense, 1987, p. 197-221.

CHAMOISEAU, Patrick. Texaco. Trad. Rosa Freire D’Aguiar. São Paulo: Companhia das Letras, 1993.

EVARISTO, Conceição. Para a menina. In: RIBEIRO, Esmeralda; BARBOSA, Márcio; FÁTIMA, Sónia (Orgs.). Cadernos Negros 21: poemas afro-brasileiros. São Paulo: Quilombhoje/Editora Anita, 1998, p. 35.

. Do velho ao jovem. In: SANTOS, Luiz Carlos; GALAS, Maria; TAVARES, Ulisses (Orgs.). O negro em versos. São Paulo: Salamandra, 2005, p. 72-73.

. Vozes -mulheres. In: Poemas de recordação e outros movimentos. Belo Horizonte: Nadyala, 2008, p. 10 - 11.

. Recordar é preciso. In: Poemas de recordação e outros movimentos. Belo Horizonte: Nadyala, 2008, p. 9.

FONSECA, Maria Nazareth Soares. Como se fosse uma colcha de memórias. In: EVARISTO, Conceição. Becos da memória. Belo Horizonte: Mazza, 2006.

FOUCAULT, Michel. Vigiar e punir: o nascimento da prisão. Trad. Ligia M. Pondé Vassallo. Petrópolis: Vozes, 1977.

MILLER, Joseph. Entrevista. O tráfico de escravos. In: FIGUEIREDO, Luciano (Org.). A era da escravidão. Rio de Janeiro: Editora Sabin, 2009, p. 35 .

MOTT, M. L. B. A criança escrava na literatura de viagens. Cadernos de Pesquisa. São Paulo: Fundação Carlos Chagas (31): 57-68, dez. 1979.

Recebido em 11 de julho e aprovado em 15 de setembro de 2010. 